\title{
Design and Model Test of a Modularized Prefabricated Steel Frame Structure with Inclined Braces
}

\author{
Xuechun Liu, ${ }^{1}$ Ailin Zhang, ${ }^{1}$ Jing Ma, ${ }^{1}$ Yongqiang Tan, ${ }^{2}$ and Yu Bai ${ }^{1}$ \\ ${ }^{1}$ Beijing Engineering Research Center of High-Rise and Large-Span Prestressed Steel Structure, Beijing University of Technology, \\ Beijing 100024, China \\ ${ }^{2}$ Broad Sustainable Building Technology Co., Ltd., Xiangyin, Hunan 414600, China
}

Correspondence should be addressed to Xuechun Liu; liuxuechun@bjut.edu.cn

Received 12 January 2015; Accepted 17 April 2015

Academic Editor: Robert Cerný

Copyright (C) 2015 Xuechun Liu et al. This is an open access article distributed under the Creative Commons Attribution License, which permits unrestricted use, distribution, and reproduction in any medium, provided the original work is properly cited.

\begin{abstract}
Modularized prefabricated steel structures have become the preferred design in the industrialization of steel structures due to their advantages of fast construction speed, high degree of industrialization, low labour intensity, and more. Prefabricated steel structures have some engineering applications, but all are low-rise structures with few applications in the field of high-rise buildings. Using finite element analysis with line and solid elements, full-scale experiments were conducted to study the single-span frame, which is the core load-bearing part of a modularized prefabricated high-rise steel frame structure with inclined braces. The mechanical mechanisms, computation methods, and design formulas of truss girders were obtained by comparing the finite element and model experiments and building a theoretical and experimental basis for the compilation of design codes. The mechanical characteristics under design load, the deformation and stress state, the elastic-plastic law of development, and the yield failure mode and mechanism under horizontal ultimate load were also obtained. Based on theoretical analysis, finite element analysis, and experiments, the design method of this frame was summarized and incorporated into the design code.
\end{abstract}

\section{Introduction}

The prefabricated steel structure is a new type of steel structure system. Compared with traditional reinforced concrete structures, the prefabricated steel structure has many advantages, including fast construction, minimal weight, low labour intensity, and high degree of industrialization; it is also a type of environmentally friendly "green" building $[1,2]$. In Europe, Japan, the United States, Canada, and other developed countries and regions, the prefabricated steel structure has been widely used [3-7] and has become the standard design for building structures, factory production, mechanized construction, and series supply [8]. However, steel structure systems are only adopted in mid- and especially low-rise buildings; they were not used in high-rise building [9-12].

In view of the fact that China has a large population and less building land, the high-rise structure is more suited to the needs of Chinese economic development, but, to the best of our knowledge, no research has been conducted on the prefabricated steel structure in high-rise buildings [13]. Recently, in China, steel overcapacity has resulted in a price advantage for steel, which is a great opportunity for the development of steel structures. The comprehensive development of prefabricated steel structures may help solve the contradiction between land resource scarcity and high housing prices in China; change a large number of rural migrant workers to industrial workers; and revolutionize building construction. The development of new and practical prefabricated steel structures has more important practical significance in realizing the industrialization of steel building and leading the development of the construction industry in a green, eco-friendly direction to save energy and reduce emissions. In conclusion, compared with the traditional structure, the prefabricated steel structure system has incomparable advantages in the aspects of building performance, construction speed, engineering quality, and environmental protection [14]. 


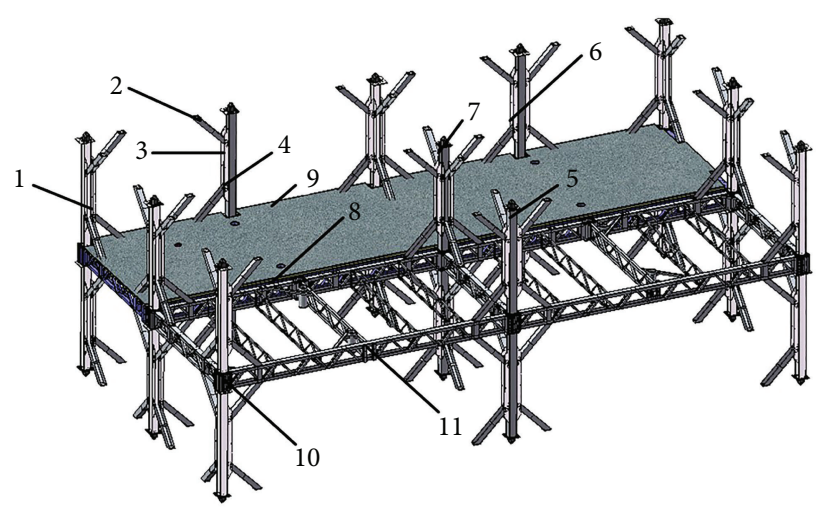

FIGURE 1: Modularized prefabricated steel frame structure with inclined braces. 1: column; 2: inclined brace; 3: column stiffening ribs; 4: single-side brace column; 5 : three-side brace column; 6: double-side brace column; 7: four-side brace column; 8: hanging box; 9: main floor; 10: column base; and 11: truss.

This paper presents a new modularized prefabricated steel frame structure with inclined braces that is suitable for highrise prefabricated building. It has advantages such as fast construction speed, high degree of industrialization, and low labour intensity; in one case, a 30-story building was built in 15 days, except for the foundation and basement. This paper presents finite element analysis and full-scale experiments conducted on the single-span frame, which is the core loadbearing part. The frame is different from the normal one which is familiar to us and has been studied, but the research method may provide some references for the research of this frame [15-17]. The mechanical mechanism, computation methods, and design formulas of truss girders were obtained and verified by the results of finite element and model experiments. The mechanical characteristics under design load, the failure modes under ultimate load, the deformation and stress state, the elastic-plastic development law, and the yield failure mode and mechanism under horizontal ultimate load were also obtained. Based on theoretical analysis, finite element analysis, and experiments, the design method of this frame was summarized and written into the design code.

\section{Structure System}

The modularized prefabricated steel frame structure with inclined braces is mainly composed of two assembly modules: the main floor and the inclined brace column, as shown in Figure 1. Factory weld connections are used inside the modules, and high strength bolts are used to connect modules on the construction site. As shown in Figure 2, the main floor consists of column bases, profiled steel sheet-concrete composite slabs, and truss girders; in fact it also includes some nonstructural members such as water pipes, air ducts, electric wires, fan coils, air conditions, and other facilities. It is like the mainboard of computer, so it is called main floor here. The steel truss beam is welded with channel steel, angle steel, and steel plate, which is convenient for installing pipes. The profiled steel sheet-concrete composite slabs and truss are joined in the factory to form the main floor, which

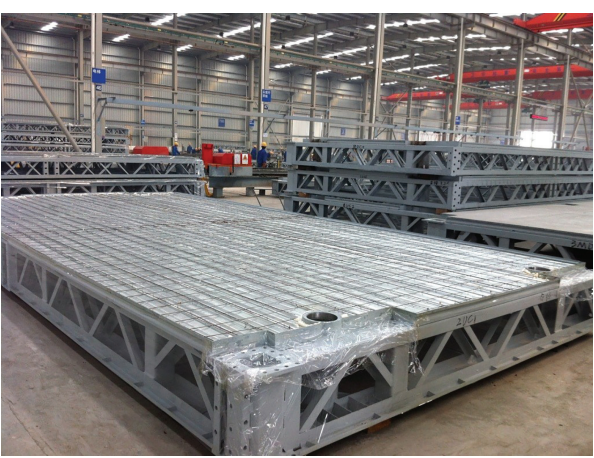

Figure 2: Main floor.

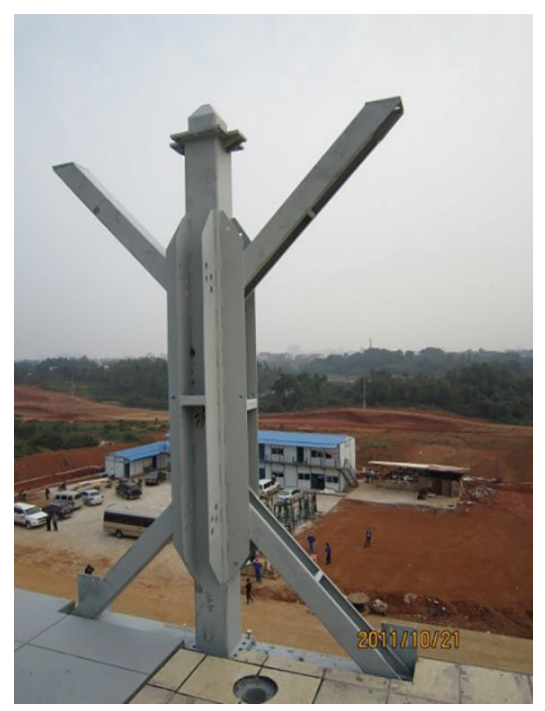

FIgURE 3: Inclined brace column.

is the assembly module for water, heating, electricity, and other utilities. Before main floors leave the factory, the floor surface decoration, ceiling, pipelines of water, heating, airconditioning, and electrical wires have been installed, and the connection interfaces between modules have also been prepared.

As shown in Figure 3, the inclined brace columns are composed of columns, column stiffening ribs, and inclined braces, which are welded together. The inclined brace only connects with the column at approximately $1 / 3$ the length of the column, and the inclined support connects with girders at a 45-degree angle, working together with the framework. As shown in Figure 4, the inclined braces of upper- and lowerlevel floors, along with the column base and truss, constitute a reinforced inclined brace joint. Columns use square tubular steel, and the inclined braces can be set in four ways (singleside brace columns, double-side brace columns, three-side brace columns, and four-side brace columns) or there may be no-brace column too.

The main floors and diagonal brace columns fabricated in the factory are connected by high strength bolts at the construction site, using the two flanges at the end of the column base and columns. After assembly, it has the following characteristics and mechanics: the brace only crosses at 


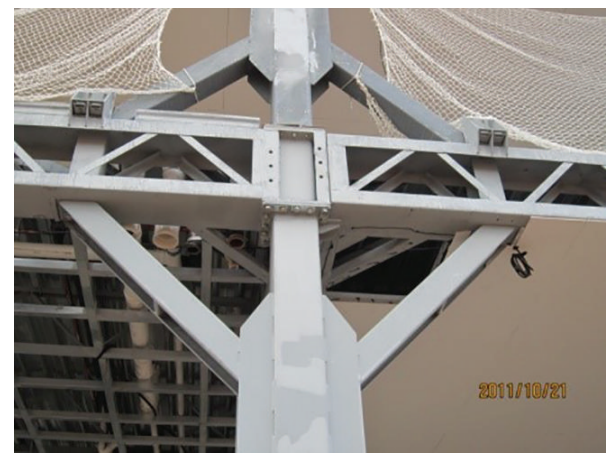

FIGURE 4: Inclined brace joint.

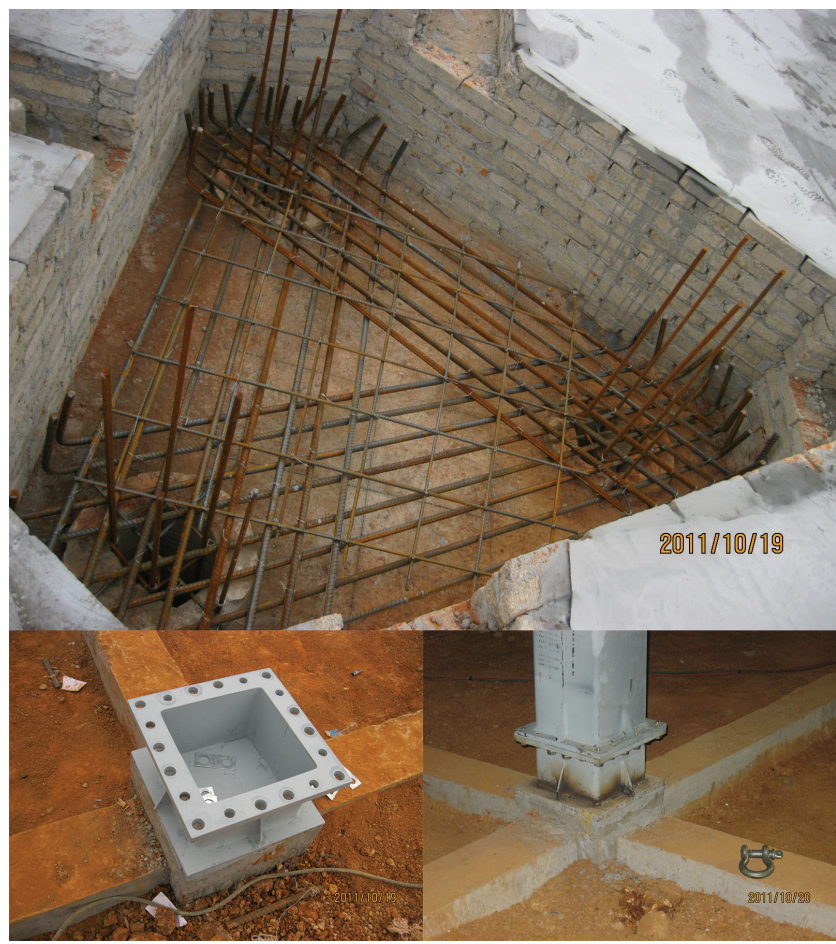

Figure 5: Foundation and connection

approximately $1 / 3$ the length of the column and does not pass through the floor, making the assembly very convenient and enabling more flexible architectural design with regard to indoor layout and the position of doors and windows. The inclined braces make beam-column connections stronger, enabling the inclined support and beam-column to resist loads together and avoid joint failure in large earthquakes. This structure follows the general trend in building industrialization, with characteristics such as design standardization, fabrication industrialization, on-site assembly, and fast construction speed; modularized prefabricated steel frame structures have broad market prospects.

\section{Construction Process and Method}

The construction of the modularized prefabricated steel frame structure with inclined braces mainly includes four steps. The first step is the construction of foundation. Some of the steel structure members are imbedded in the foundation during its construction, as shown in Figure 5; the

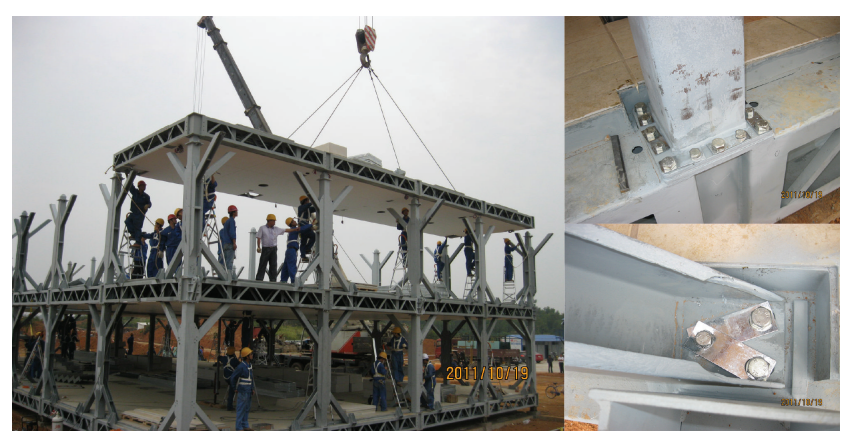

FIGURE 6: Assembly of modules.

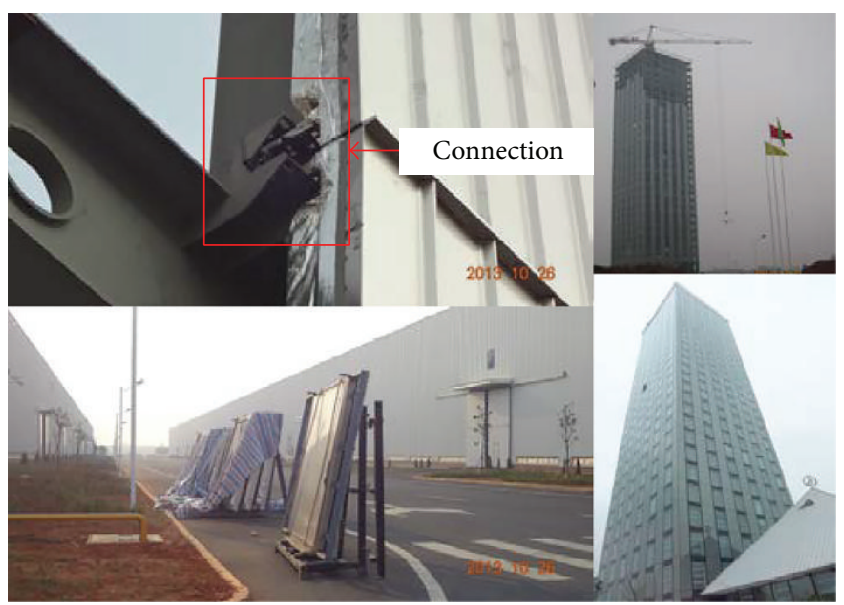

FIGURE 7: Installation of outer wall.

connections for column are above the foundation. Figure 5 shows the example of a pile foundation. The second step is the installation of inclined brace columns and main floors, as shown in Figure 6. The flange of column is bolted to the flange of column base in the main floor and the inclined brace is bolted to upper or lower chord of truss. In this way, the structure is constructed one floor by one floor. The third step is the installation of outer wall. As shown in Figure 7, the outer wall is a large piece including the inner skin, heat insulation, window, and outer cover, which are fabricated in factory. It is integral hanged and bolted to the joint on the truss. The last step is the construction of interior wall and indoor decoration.

\section{Calculation and Test Model}

The inclined brace frame is the core part of the structure. To study the design method, one single-span frame is chosen as the research object for finite element analysis and design formula derivation, and two frames are chosen for the model experiment verification. As shown in Figure 8, the frame columns are cut between the upper and lower inflection points and hinged at the bottom inflection points. The frame is upside down to compare it with the model test. The outof-plane instability of the top chords of the truss is restricted by the concrete slab; out-of-plane constraints are applied on the nodes of the top chord, so only the strength calculation is needed. The out-of-plane restrictions of the lower chords 


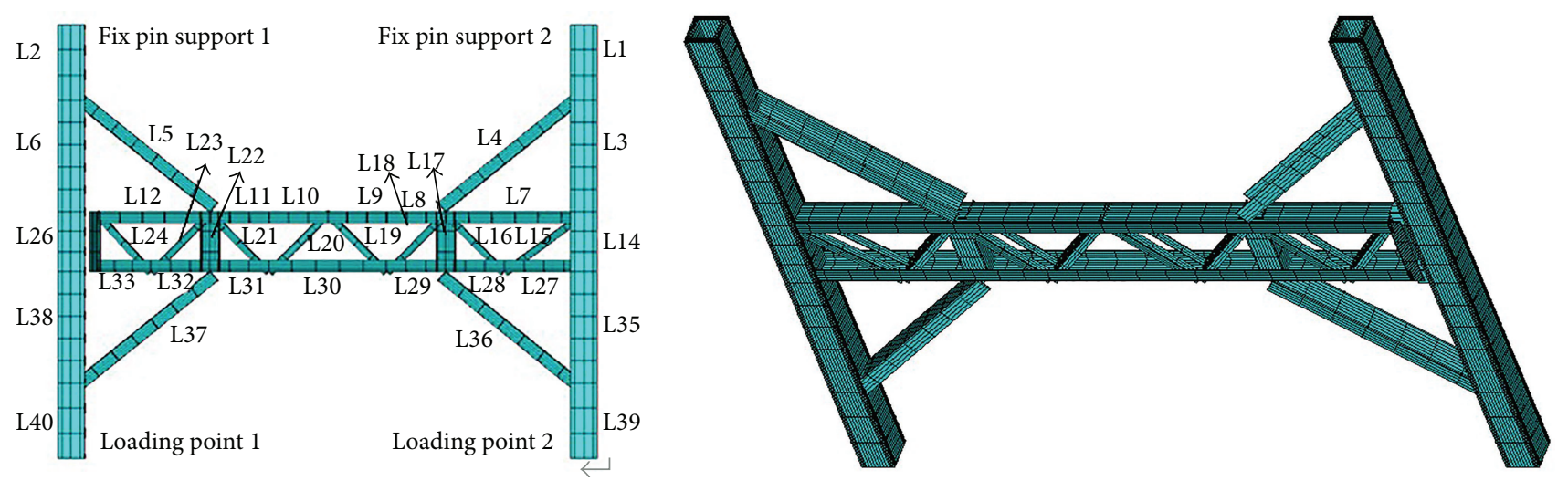

(a) Line element model
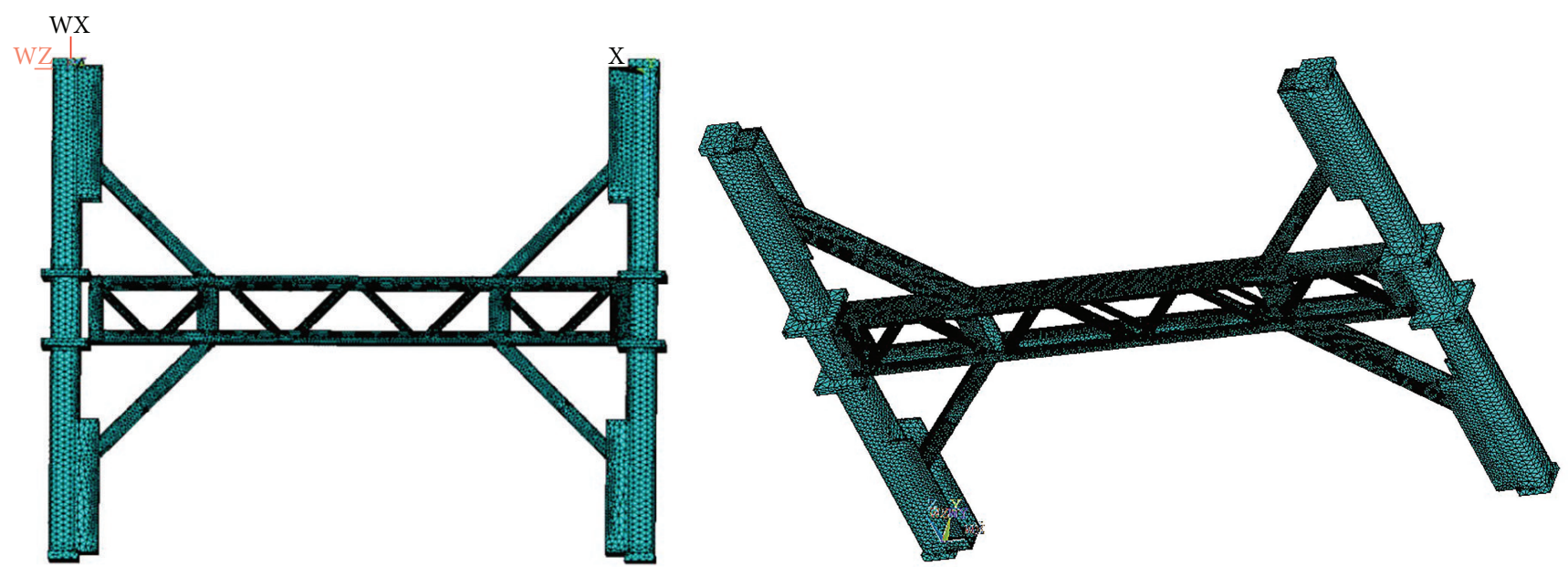

(b) Solid element model

Figure 8: Element model and member number.

TABLE 1: Member sizes.

\begin{tabular}{lc}
\hline Member & Size \\
\hline Chord members of truss girders & $\mathrm{C} 160 \times 80 \times 8$ \\
Web members of truss girders & $2 \mathrm{~L} 50 \times 5$ \\
Column & $200 \times 200 \times 30$ \\
Support foot & $\mathrm{C} 135 \times 135 \times 12$ \\
Inclined brace & $\mathrm{C} 160 \times 90 \times 10$ \\
\hline
\end{tabular}

are applied by the secondary beam at the intersection. Both ends of the web member are restricted by the upper and lower chords, respectively, in the in-plane and out-of-plane directions. To research the mechanical characteristics of the frame in the actual structure, the maximum axial force of the column under the equivalent gravity load in structural integral analysis, $3000 \mathrm{kN}$, is applied at the top of each column, with an axial compression ratio of 0.474 . Horizontal forces are applied on each column to simulate the wind load and horizontal seismic action. Finite element simulation models and component numbers are shown in Figure 4. The section sizes of members are shown in Table 1.

The BEAM189 element of ANSYS is used as the line element and the SOLID187 element as the solid element in simulation. The BEAM189 element is suitable for analyzing slender to moderately stubby/thick beam structures. The element is based on Timoshenko's beam theory which includes shear-deformation effects. The element provides options for unrestrained warping and restrained warping of cross-sections. The element is a quadratic three-node beam element in 3D. Six degrees of freedom occur at each node; these include translations in the $x$-, $y$-, and $z$-directions and rotations about the $x$-, $y$-, and $z$-directions. The element is well suited for linear, large-rotation, and/or large-strain nonlinear applications. The element includes stress-stiffness terms. The provided stress-stiffness terms enable the elements to analyze flexural, lateral, and torsional stability problems. The elasticity, plasticity, creep, and other nonlinear material models are supported. The BEAM189 element can simulate the C-type and Box section of the frame by section definition very well. The SOLID187 element is a higher-order 3D, 10node element. It has a quadratic displacement behavior and is well suited to modeling irregular meshes. The element is defined by 10 nodes having three degrees of freedom at each node: translations in the nodal $x$-, $y$-, and $z$-directions. The element has plasticity, hyperelasticity, creep, stress stiffening, large deflection, and large strain capabilities. 
For both line element model and solid element model, the inclined brace and top chord are rigidly connected together. The chord and web are rigidly connected too. The bottom point of the columns is fixed pin support. The vertical and horizontal loads are applied on the top of the columns. The out-of-plane degree of freedom of joints in top chord is constrained, and the out-of plane degree of freedom of points which are connected with secondary beam is constrained; the boundary conditions are the same as that of the frame in integral structure. The max length of line element is $19.7 \mathrm{~cm}$; the max volume of solid element is $33.2 \mathrm{~cm}^{3}$.

The initial bending defect of 2/1000 length of the members was introduced to the members for the global stability analysis of members by ANSYS software. First the $x, y$, and $z$ degrees of freedom of the joints between all members are constrained and the static analysis is performed on the model under dead weight. Then the modal analysis is performed under the stress of static analysis. The maximum deformation of every member is got by modal analysis. The model is revised according to the modal shape and the maximum deformation of every member is $2 / 1000$ length of the members. At last, the integral stability analysis is performed on the model. On this way, the initial geometry defection is considered.

The material for the truss, inclined brace, and column is Q345B, which is used in the Chinese standard [18], the elastic modulus is $2.06 \times 10^{5} \mathrm{~N} / \mathrm{mm}^{2}$, the Poisson ratio is 0.3 , and the density is $7.85 \times 10^{-3} \mathrm{~g} / \mathrm{mm}^{3}$. After the transformation, the true stress-strain relationship is shown in Figure 9.

\section{Stiffness Calculation Hypothesis of Chord Connection}

To study the effect of the connection stiffness of web members, chords, and inclined braces, it is assumed that the connections are rigid and hinged, respectively, and the actual member stresses are obtained using ANSYS finite element analysis, as shown in Figure 10. As shown in Figure 10, the actual stresses in web members, chords, and inclined braces differ significantly between the rigid and hinged connection assumptions, which indicates that the stress induced by the end bending moment cannot be ignored. Moreover, the chord is continuous steel channel at the joint, and the web member is inserted into the channel and welded with the flange and web of the channel; therefore, the connections between web members and chords should be rigid connection in the calculation. The stress on the inclined brace with the two endconnection assumptions differed immensely, up to $66.84 \%$. Moreover, one end of the brace is welded with the column, the other end is bolted to truss, and each end can resist enough moment; therefore, the connections at both ends of the braces should be rigid connection in the calculation model.

\section{Member Design}

6.1. Design of Upper Truss Chords. The upper chords of the truss are made of channel steel and are the compressionbending members subjected to the axial force and biaxial bending moment. The upper chords are reliably connected

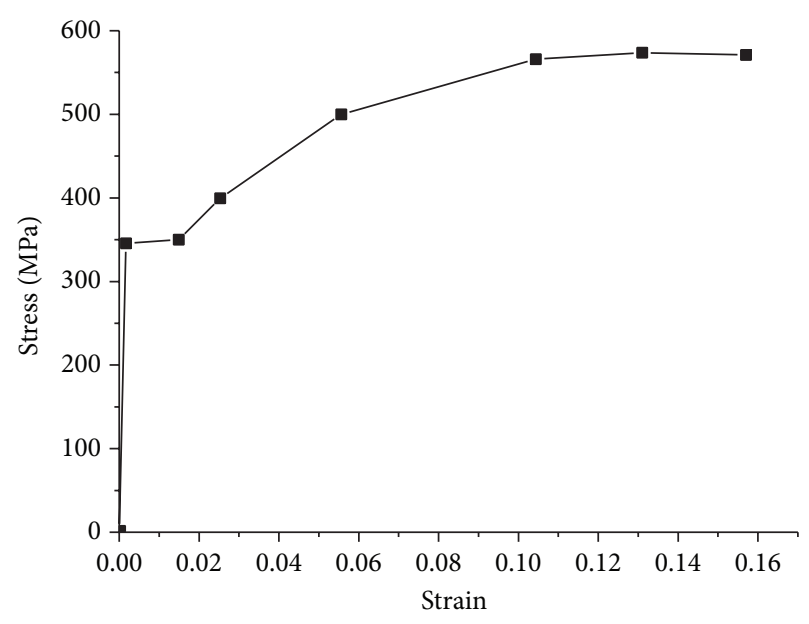

FIGURE 9: Stress-strain curve.

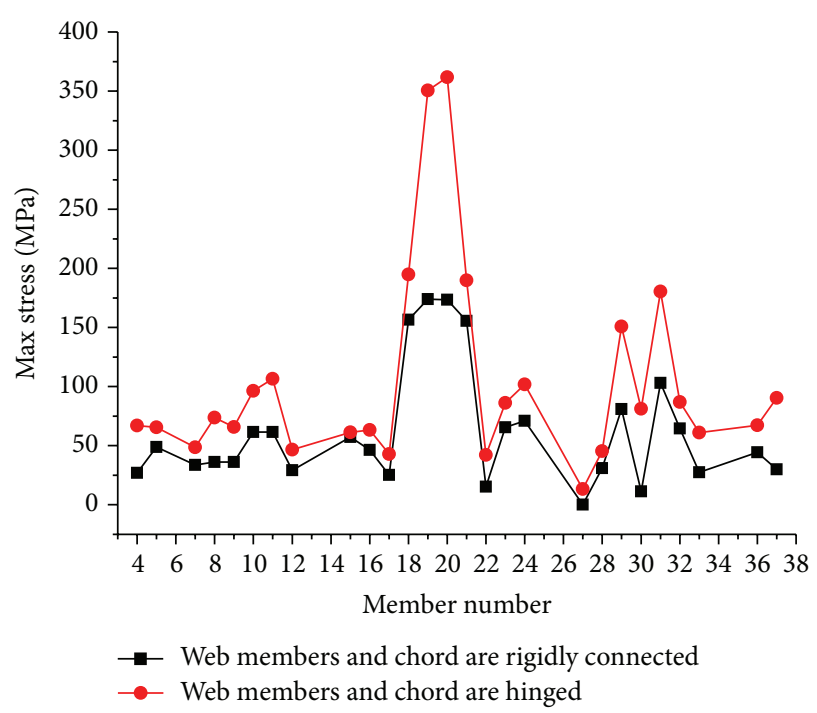

Figure 10: Member maximum stress comparative analysis.

to the concrete slab by studs, which are welded along the top of the upper chords at constant intervals. The slab restricts the out-of-plane and in-plane instability of the upper chords, so only the chord strength should be calculated, regardless of the stability calculation. Without concrete slabs, the upper chords' in-plane effective length is the length between the joints, and the out-of-plane effective length is the distance between lateral supporting joints. The strengths of points 1 to 4 , shown in Figure 11, are calculated according to formulas (1) to (4), and stability around the $x$ - and $y$-axes is calculated according to formulas (5) to (10) [19].

When both moments produce pressure at point 1 ,

$$
\frac{N}{A_{n}}-\frac{0.9 M_{x}}{\gamma_{1 x} W_{1 n x}}+\frac{0.9 M_{y}}{\gamma_{1 y} W_{1 n y}} \leq \frac{f}{\gamma_{\mathrm{RE}}} .
$$

When both moments produce pressure at point 2 ,

$$
\frac{N}{A_{n}}+\frac{0.9 M_{x}}{\gamma_{2 x} W_{2 n x}}+\frac{0.9 M_{y}}{\gamma_{2 y} W_{2 n y}} \leq \frac{f}{\gamma_{\mathrm{RE}}} .
$$




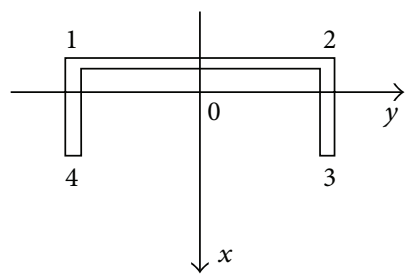

FIGURE 11: Upper chord.

When both moments produce pressure at point 3,

$$
\frac{N}{A_{n}}+\frac{0.9 M_{x}}{\gamma_{3 x} W_{3 n x}}-\frac{0.9 M_{y}}{\gamma_{3 y} W_{3 n y}} \leq \frac{f}{\gamma_{\mathrm{RE}}} .
$$

When both moments produce pressure at point 4,

$$
\frac{N}{A_{n}}-\frac{0.9 M_{x}}{\gamma_{4 x} W_{4 n x}}-\frac{0.9 M_{y}}{\gamma_{4 y} W_{4 n y}} \leq \frac{f}{\gamma_{\mathrm{RE}}} .
$$

When both moments produce pressure at point 1 ,

$$
\begin{aligned}
& \frac{N}{\varphi_{x} A}-\frac{\beta_{m x} \cdot 0.9 M_{x}}{\gamma_{1 x} W_{1 x}\left(1-0.8 \frac{N}{N_{E x}^{\prime}}\right)}+\eta \frac{\beta_{t y} \cdot 0.9 M_{y}}{W_{1 y}} \leq \frac{f}{\gamma_{\mathrm{RE}}} \\
& \frac{N}{\varphi_{y} A}-\eta \frac{\beta_{t x} \cdot 0.9 M_{x}}{W_{1 x}}+\frac{\beta_{m y} \cdot 0.9 M_{y}}{\gamma_{1 y} W_{1 y}\left(1-0.8 \frac{N}{N_{E y}^{\prime}}\right)} \\
& \leq \frac{f}{\gamma_{\mathrm{RE}}} .
\end{aligned}
$$

When both moments produce pressure at point 2 ,

$$
\begin{gathered}
\frac{N}{\varphi_{x} A}+\frac{\beta_{m x} \cdot 0.9 M_{x}}{\gamma_{2 x} W_{2 x}\left(1-0.8 \frac{N}{N_{E x}^{\prime}}\right)}+\eta \frac{\beta_{t y} \cdot 0.9 M_{y}}{W_{2 y}} \leq \frac{f}{\gamma_{\mathrm{RE}}} \\
\frac{N}{\varphi_{y} A}+\eta \frac{\beta_{t x} \cdot 0.9 M_{x}}{W_{2 x}}+\frac{\beta_{m y} \cdot 0.9 M_{y}}{\gamma_{2 y} W_{2 y}\left(1-0.8 \frac{N}{N_{E y}^{\prime}}\right)} \leq \frac{f}{\gamma_{\mathrm{RE}}} .
\end{gathered}
$$

When both moments produce pressure at point 3,

$$
\begin{gathered}
\frac{N}{\varphi_{x} A}+\frac{\beta_{m x} \cdot 0.9 M_{x}}{\gamma_{3 x} W_{3 x}\left(1-0.8 \frac{N}{N_{E x}^{\prime}}\right)}-\eta \frac{\beta_{t y} \cdot 0.9 M_{y}}{W_{3 y}} \leq \frac{f}{\gamma_{\mathrm{RE}}} \\
\frac{N}{\varphi_{y} A}+\eta \frac{\beta_{t x} \cdot 0.9 M_{x}}{W_{3 x}}-\frac{\beta_{m y} \cdot 0.9 M_{y}}{\gamma_{3 y} W_{3 y}\left(1-0.8 \frac{N}{N_{E y}^{\prime}}\right)} \leq \frac{f}{\gamma_{\mathrm{RE}}} .
\end{gathered}
$$

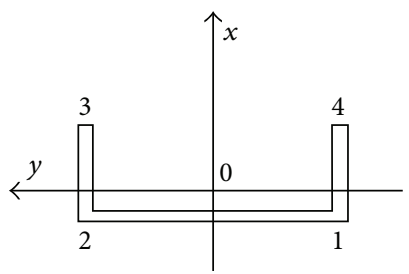

FIGURE 12: Lower chord.

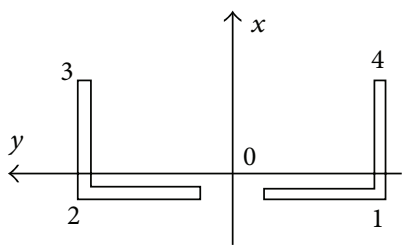

Figure 13: Web member.

When both moments produce pressure at point 4 ,

$$
\begin{aligned}
& \frac{N}{\varphi_{x} A}-\frac{\beta_{m x} \cdot 0.9 M_{x}}{\gamma_{4 x} W_{4 x}\left(1-0.8 \frac{N}{N_{E x}^{\prime}}\right)}-\eta \frac{\beta_{t y} \cdot 0.9 M_{y}}{W_{4 y}} \\
& \quad \leq \frac{f}{\gamma_{\mathrm{RE}}} \\
& \frac{N}{\varphi_{y} A}-\eta \frac{\beta_{t x} \cdot 0.9 M_{x}}{W_{4 x}}-\frac{\beta_{m y} \cdot 0.9 M_{y}}{\gamma_{4 y} W_{4 y}\left(1-0.8 \frac{N}{N_{E y}^{\prime}}\right)} \\
& \leq \frac{f}{\gamma_{\mathrm{RE}}} \\
& N_{E x}^{\prime}=\frac{\pi^{2} E A}{\left(1.1 \lambda_{x}^{2}\right)} \\
& N_{E y}^{\prime}=\frac{\pi^{2} E A}{\left(1.1 \lambda_{y}^{2}\right)} .
\end{aligned}
$$

6.2. Design of Lower Truss Chords. The lower chords of the truss are made of a steel channel and are the compressionbending members subjected to axial force and biaxial bending moment. The in-plane effective length is the length between the joints, and the out-of-plane effective length is the distance between lateral supporting joints. The strengths of points 1 to 4, shown in Figure 12, are calculated according to formulas (1) to (4), and stability around the $x$ - and $y$-axes is calculated according to formulas (5) to (10).

6.3. Design of Truss Web Member. The web member of the truss is made of two L-shaped steel angles and is simplified as the individual component subjected to axial force and biaxial bending moments. The in-plane and out-of-plane calculation lengths are 0.8 times the length between the joints. The strengths of points 1 to 4 , shown in Figure 13, are calculated according to formulas (1) to (4), and the stability around the $x$ - and $y$-axes is calculated according to formulas (5) to (10). 


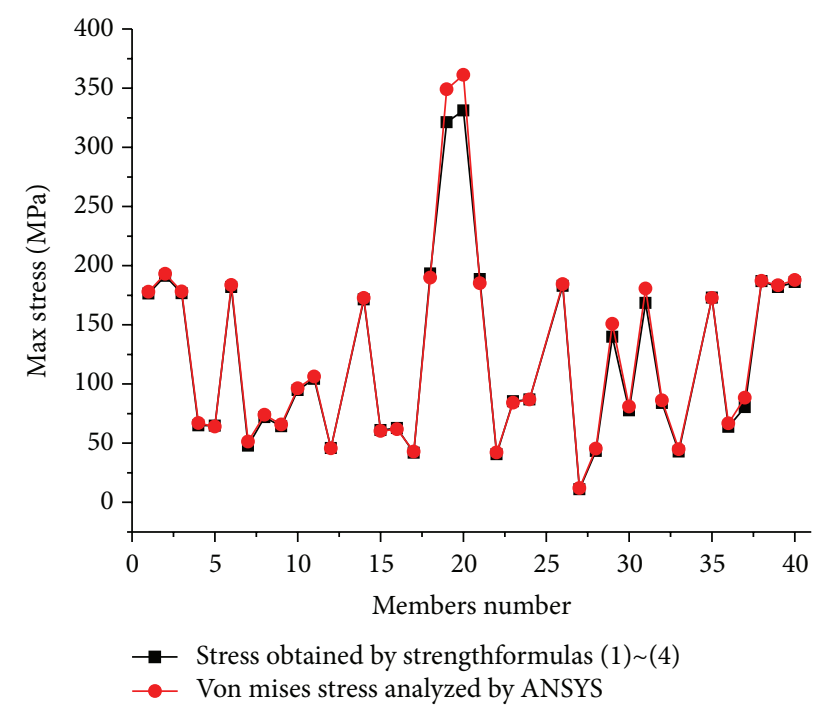

FIgURE 14: Comparison of results between strength formulas and finite element analysis.

6.4. Component Strength Design. Temporarily disregarding defects, the results of the ANSYS finite element analysis using line elements are compared with the results of strength calculations using (1)-(4) above. To accurately compare results, the plastic development coefficient is temporarily assumed to be 1.0 in the formulas. A $3000 \mathrm{kN}$ vertical force and a $59 \mathrm{kN}$ horizontal force are applied at the top of each column. The results are shown in Figure 14.

Because line elements were used in the design software, the joint between the members was a point without size. However, the members in the actual structure overlapped at the joint, which was a region rather than a point. The maximum bending moment occurred at the end of member in real structure, but the maximum bending moment calculated by line elements occurred at the joint, which was a region in the real structure. Due to the overlap of members in the joint region and additional components of the joint, the strength and stiffness of joint were larger than those of members. Thus, the bending moment in the joint region did not affect the member strength. The maximum bending moment outside of the joint region should be the design moment of the members. According to the structure characteristics, the member length is rather small, and the joint is approximately $8 \mathrm{~cm}$, so 0.9 is used as the reduction factor for the end moment of chord and web members. Because the column section is larger and the joint region is relatively small compared to the column, there is no reduction for the end moment of the column. As shown in Figure 14, the equivalent column stresses obtained by the design formulas and by second-order analysis with ANSYS are almost equal. The other components, due to the reduction of the end moment, differ by less than $8 \%$. The result of finite element analysis is very close to that of the strength calculation formulas above, which proves the strength calculation formulas.

6.5. Design of Member Stability. The global stability analysis was conducted using the finite element software ANSYS,
TABLE 2: Comparison between stability formulas and finite element analysis (positive load).

\begin{tabular}{lcc}
\hline Member number & $\begin{array}{c}\text { Equivalent stress by } \\
\text { stability formulas } \\
(5) \sim(10)\end{array}$ & $\begin{array}{c}\text { Equivalent stress by } \\
\text { finite element analysis } \\
\text { considering defects }\end{array}$ \\
\hline 19 & 310 & 345 \\
33 & 323 & 335 \\
18 & 325 & 345 \\
20 & 307 & 345 \\
\hline
\end{tabular}

TABLE 3: Comparison between stability formulas and finite element analysis (negative load).

\begin{tabular}{lcc}
\hline Member number & $\begin{array}{c}\text { Equivalent stress by } \\
\text { stability formulas } \\
(5) \sim(10)\end{array}$ & $\begin{array}{c}\text { Equivalent stress by } \\
\text { finite element analysis } \\
\text { considering defects }\end{array}$ \\
\hline 7 & 311 & 345 \\
31 & 298 & 345 \\
9 & 275 & 345 \\
8 & 310 & 345 \\
18 & 339 & 345 \\
20 & 314 & 346 \\
\hline
\end{tabular}

which considers geometric nonlinearity and material nonlinearity of the member with an initial bending defect of 2/1000 length of members. Based on the marginal fibre yield criterion, when the stress of the marginal fibre of the member with the initial defect reaches a yield strength of $345 \mathrm{MPa}$, the member reaches the stability limit state. The horizontal load under the stability limit state is applied on the structure without defects, and the internal force of the member is used for the stability calculation with the formulas above. The stability calculation and finite element analysis results for compression members when the frame is loaded in the positive direction are listed in Table 2. The stability calculation and finite element analysis results for compression members when the frame is loaded in the negative direction are listed in Table 3. If the calculated equivalent critical stress is equal to the design strength, $310 \mathrm{MPa}$, the calculated result is in accord with that of finite element analysis, which verifies the formulas.

As shown in Tables 2 and 3, due to the differences in position, length, and section forms, the members had varying degrees of sensitivity to defects. However, when the equivalent stress by second-order analysis reaches $345 \mathrm{MPa}$, that is, the margin fibre yield state, the equivalent stress yielded by the stability calculation is approximately $310 \mathrm{MPa}$. So the above formulas (5)-(10) can be used for the stability design of frame members.

\section{Static Testing and Comparison}

7.1. Layout of Load and Displacement. To verify the strength and stability calculation formulas, static loading tests were conducted on two identical single-span frames. The geometric model and loading conditions in the test are the same as 


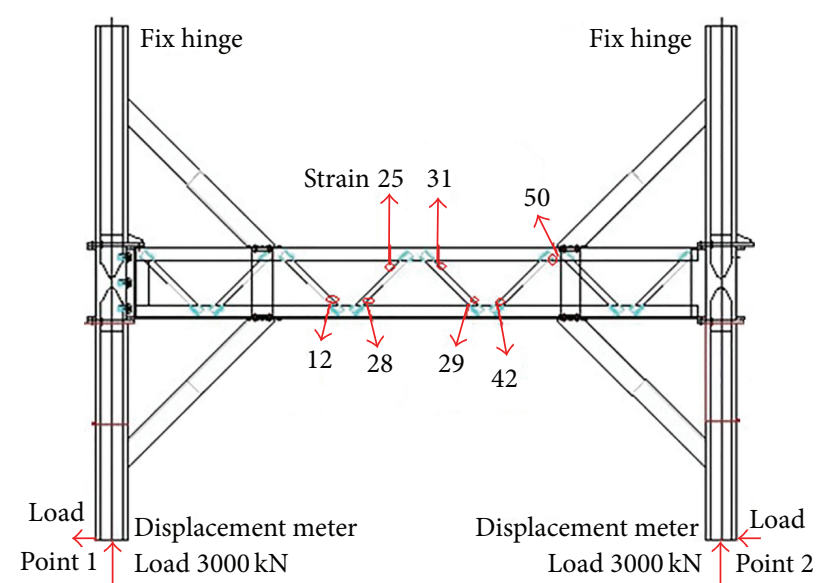

Figure 15: Sketch of test setup.

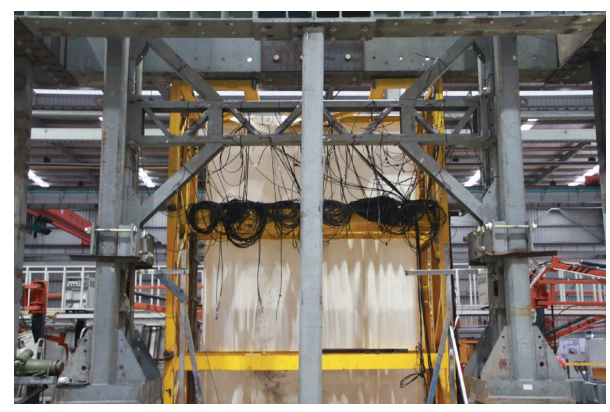

Figure 16: Test setup.

those in the finite element analysis above. Because the specimen hung upside down in the test device, the vertical load F1 is applied upward at the bottom of the columns to simulate the load of the upper structure; the horizontal load F2 is applied at the bottom of the columns, in the positive direction, as shown in Figure 15. The loads, major strain gages, and displacement meters are arranged as shown in Figure 15, and the test setup is shown in Figure 16.

7.2. Experimental Phenomena and Results. The load-displacement curves of the column tops are shown in Figure 17; the curves of the finite element analysis using line elements and solid elements are close to the test curves when the load is very small, but the deviation increases as the horizontal load increases. According to the load-displacement curve of line elements where web members have rigid connections to the chord, when the horizontal load is less than $110 \mathrm{kN}$, the curve is straight; when the load increases a little more, the curve becomes almost horizontal, and the structure is destroyed. According to the load-displacement curve for line elements where web members have hinge connections to the chord, when the horizontal load is less than $159 \mathrm{kN}$, the curve is straight and the structure is destroyed when the load continues to increase. According to the load-displacement curve for solid elements, when the horizontal load is less than $70 \mathrm{kN}$, the curve is straight and then begins to bend, and, finally, the frame is destroyed when the horizontal load

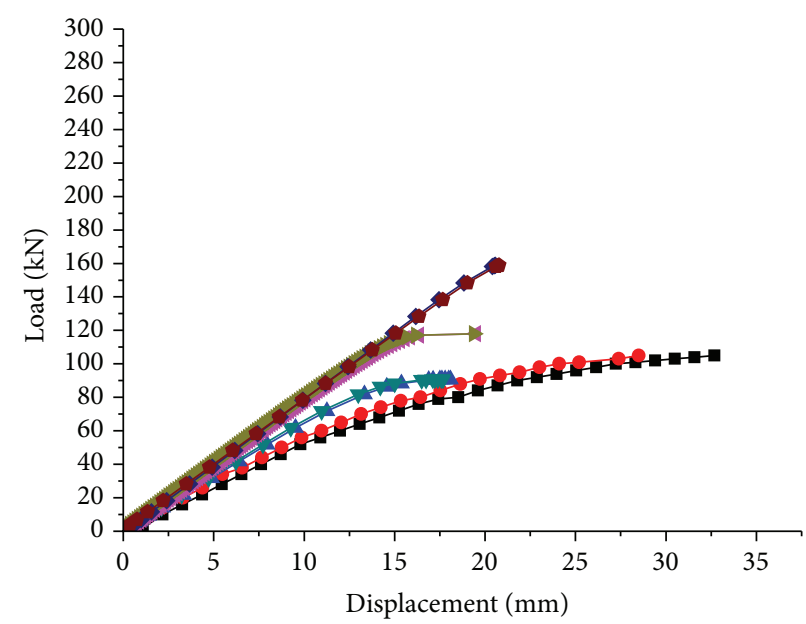

$\rightarrow$ - Point 1 test curve

$\rightarrow$ Point 2 test curve

- - Point 1 solid element curve

$\rightarrow$ Point 2 solid element curve

- Point 1 line element curve (web member rigid connected)

$\rightarrow$ Point 2 line element curve (web member rigid connected)

$\neg$ Point 1 line element curve (web member hinge connected)

- - Point 2 line element curve (web member hinge connected)

FIgURE 17: Load-displacement curves at column tops.

reaches $90 \mathrm{kN}$. However, the model test indicates that when the horizontal load is less than $60 \mathrm{kN}$, the curve is basically straight; when the horizontal load is over $60 \mathrm{kN}$, the curve begins to bend, which indicates that the frame is in the elastic-plastic state; when the horizontal load reaches $105 \mathrm{kN}$, the horizontal displacement reached $28 \mathrm{~mm}$, the second web members near the inclined brace failed to bend, and the frame could not be loaded continuously, meaning that it had reached the ultimate limit state. The differences between the four pair curves show that the simulated stiffness of line elements is greater than the real stiffness. The main reason for this is that the truss uses thin-wall open sections, and the high local stress on the open section induced local out-of-plane deformation, which reduced the member stiffness. If $59 \mathrm{kN}$ is used as the design load, the standard value of the design load is $59 / 1.3=45.4 \mathrm{kN}$, and the corresponding displacements of the three methods are $5.83 \mathrm{~mm}, 6.97 \mathrm{~mm}$, and $8.61 \mathrm{~mm}$, which indicates that the line element analysis displacements are $50 \%$ smaller. This deviation should be considered in the design; the displacement calculated using line elements should be magnified 1.5 times, and the stiffness reduction factor is 0.68 . The ultimate bearing capacity obtained by line element analysis with web members having hinge connections to the chord is large and deviates from test results, which shows that the ends of the web members are rigid connected instead of being hinge connected.

As shown in Figures 18, 19, and 20, when the horizontal load is $24 \mathrm{kN}$, the structure maximum stress is quite small and occurred at columns. As shown in Figure 21, the number 42 strain exceeded the yielding strain. This is because the stress concentration exists in the joints of web members and chord members. When the horizontal load exceeded $59 \mathrm{kN}$ and 


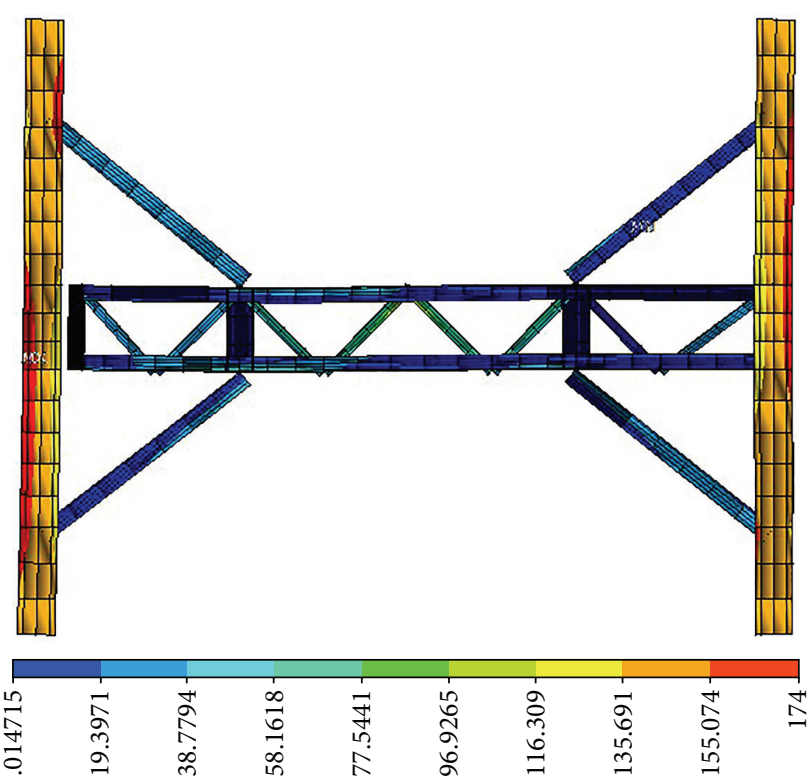

FIGURE 18: Stress when horizontal load is $24 \mathrm{kN}$.

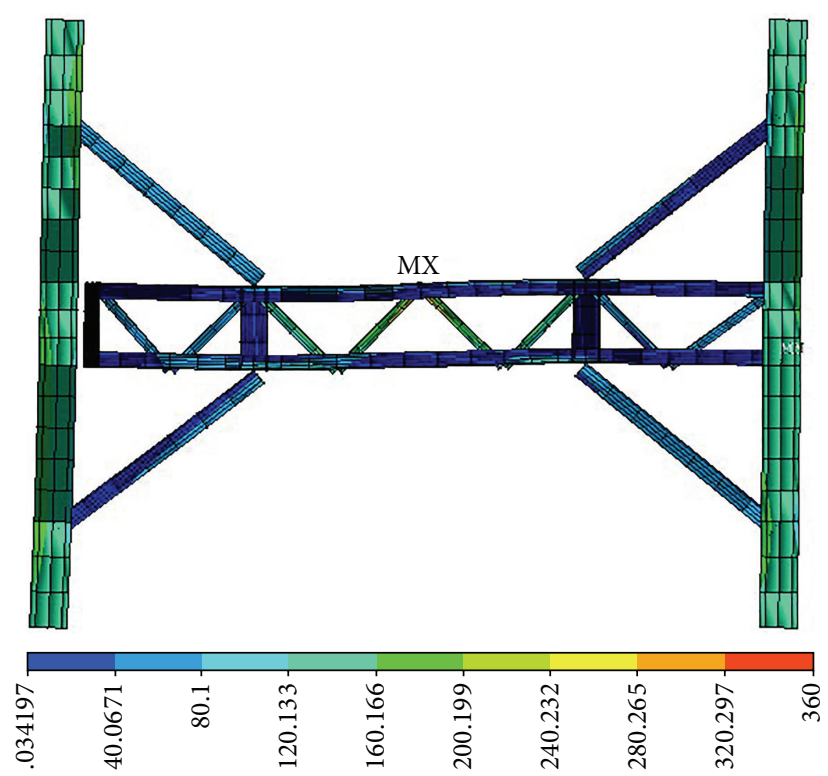

FIGURE 19: Stress when horizontal load is $59 \mathrm{kN}$.

the horizontal displacement exceeded $11 \mathrm{~mm}$, the experimental load-displacement curve began to bend, indicating that the frame entered the elastic-plastic state. The finite element analysis shows that the stress of the end of the web members in the mid-span of the truss exceeds yielding strength, which corresponds with the number 28 and number 29 strains in tests exceeding yielding strain. Both tests and FEM analysis demonstrate that the frame enters the elastic-plastic state, so this state is used as the design limit state. Using formulas under this state, the design shows that the equivalent stress ratios of the web members number 19 and number 20 are 0.99 and 1.01, respectively, which are exactly at the design limit state. Under the load, the yielding area mainly focuses on

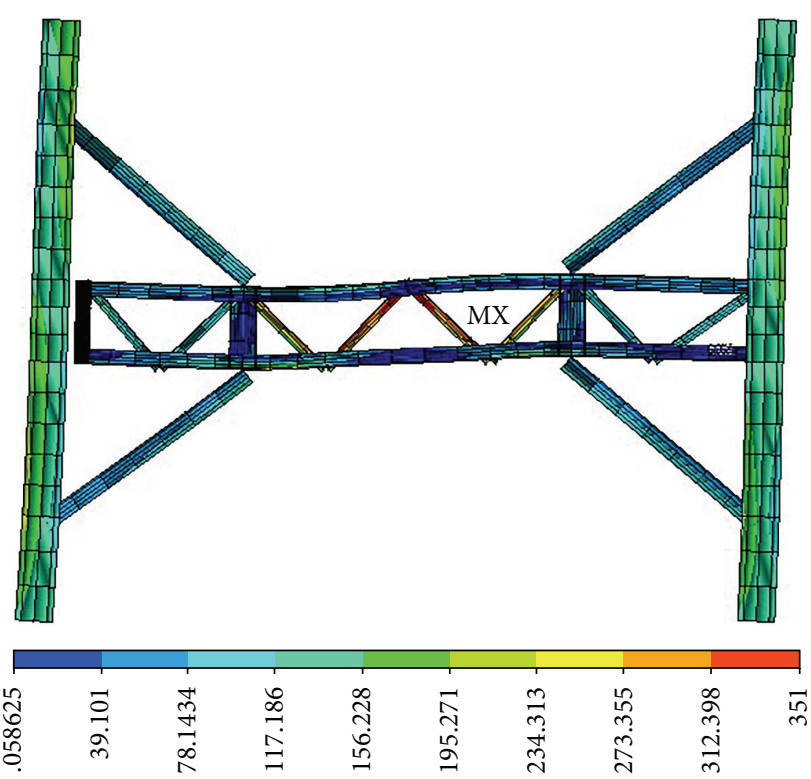

FIgURE 20: Stress when horizontal load is $105 \mathrm{kN}$.

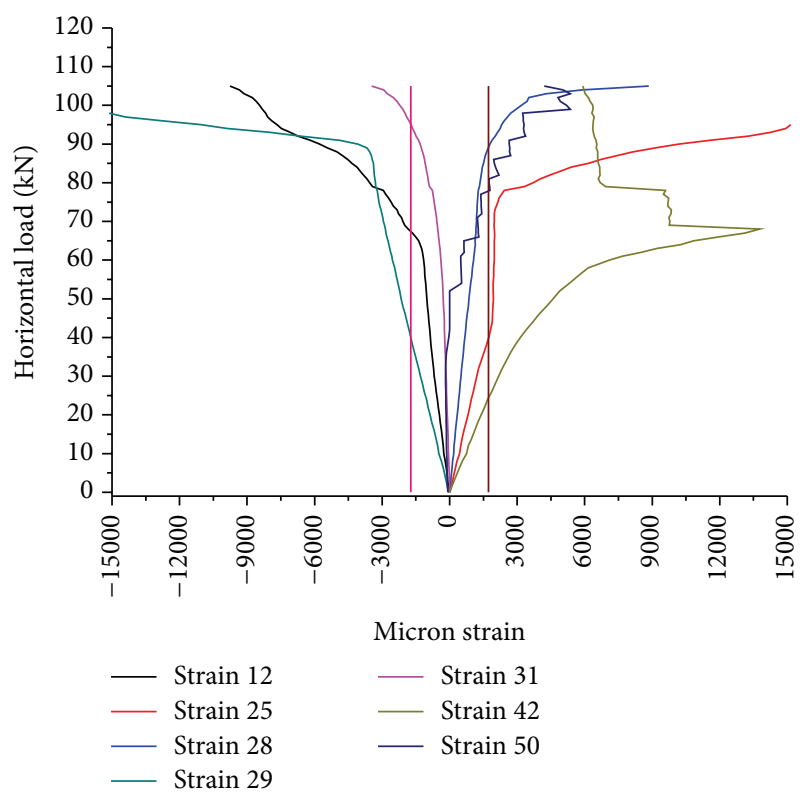

Figure 21: Load-strain curve.

an area at the end of web members, and some plasticity develops in the frame. Thus, taking the $59 \mathrm{kN}$ horizontal load as the design load is economical and safe.

According to the test results, when the horizontal load reached $105 \mathrm{kN}$, the horizontal displacement reached $28 \mathrm{~mm}$ and the second web member near the inclined brace failed; the failure mode is shown in Figure 22. The FEM analysis indicates that although the member does not lose stability, most regions of the web member section yield, showing almost full plasticity, and the calculated ultimate load is $118 \mathrm{kN}$, which is higher than that of the experiment. This is because the finite element analysis does not include the impact of the initial geometric defect, residual stress, stress 


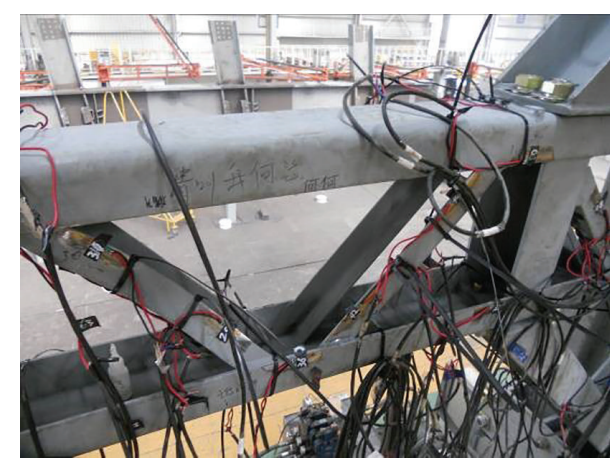

(a) Picture 1

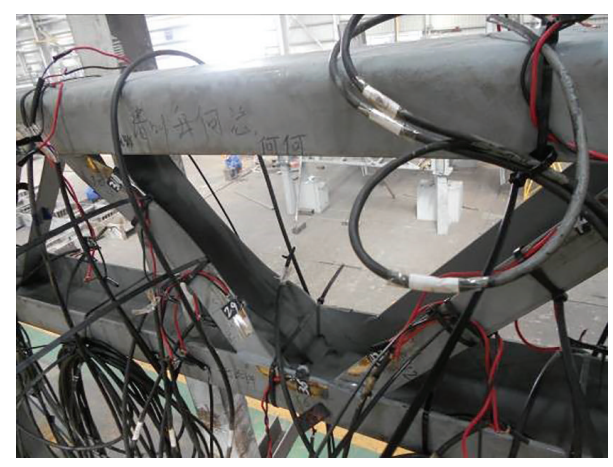

(b) Picture 2

FIgURE 22: Failure mode under ultimate load.

TABLE 4: Comparison of mechanical performance under three load states.

\begin{tabular}{lccc}
\hline Horizontal load & 24 kN & $59 \mathrm{kN}$ & $105 \mathrm{kN}$ \\
Specimen 1 & $\begin{array}{c}\text { There are small yielding zones in } \\
\text { the connections between web } \\
\text { members and chord members }\end{array}$ & $\begin{array}{c}\text { Strain gages } 25 \text { and } 29 \text { yield; the } \\
\text { ends of web members yield }\end{array}$ & $\begin{array}{c}\text { Number 20 web member } \\
\text { buckles, and story drift angles } \\
\text { are } 1 / 101 \text { and } 1 / 116\end{array}$ \\
\hline Specimen 2 & $\begin{array}{c}\text { There are small yielding zones in } \\
\text { the connection between web } \\
\text { members and chord members }\end{array}$ & $\begin{array}{c}\text { Strain gages } 28 \text { and } 29 \text { yield; the } \\
\text { ends of web members yield }\end{array}$ & $\begin{array}{c}\text { Number 20 web member } \\
\text { buckles, and story drift angles } \\
\text { are } 1 / 102 \text { and } 1 / 115\end{array}$ \\
\hline $\begin{array}{l}\text { Finite element analysis using line } \\
\text { elements }\end{array}$ & $\begin{array}{c}\text { The maximum stress } 177 \mathrm{MPa} \\
\text { occurred on the column }\end{array}$ & $\begin{array}{c}\text { The maximum stress of web } \\
\text { members is } 360 \mathrm{MPa}\end{array}$ & $\begin{array}{c}\text { The axial average stress of } \\
\text { reaches design strength, and } \\
\text { story drift angles are } 1 / 169 \text { and } \\
1 / 170\end{array}$ \\
\hline $\begin{array}{l}\text { Equivalent stress ratio using } \\
\text { design formulas }\end{array}$ & $\begin{array}{c}\text { Numbers } 19 \text { and } 20 \text { members are } \\
0.46 \text { and } 0.45\end{array}$ & $\begin{array}{c}\text { Numbers } 19 \text { and } 20 \text { members are } \\
0.99 \text { and } 1.01\end{array}$ & $\begin{array}{c}\text { Numbers } 19 \text { and } 20 \text { members are } \\
1.14 \text { and } 1.24\end{array}$ \\
\hline
\end{tabular}

concentration, and local buckling on the integral stability of the member. The ultimate load of the frame is $105 \mathrm{kN}$, and the ratio to the design load $59 \mathrm{kN}$ is 1.78 , which has a certain safety margin. According to the above analysis, taking the load $59 \mathrm{kN}$ as the design load is reasonable.

As shown in the load-displacement curve for the experiment, the story drift angles of horizontal load $59 \mathrm{kN}$ are $1 / 282$ and $1 / 309$, while those of the finite element analysis are $1 / 439$ and $1 / 450$ using line elements and $1 / 364$ and $1 / 375$ using solid elements. As shown in Table 4, the maximum ultimate story drift angle of the experiment is $1 / 101$ and 1/115 when the web members failed by buckling and lost their bearing capacity. Thus the inclined brace can enhance the lateral stiffness of the frame but reduce the lateral deformability.

\section{Conclusions}

Taking the finite element analysis of line elements and solid elements and two model tests and comparing these with the design formulas, the following conclusions have been drawn.

(1) Some plastic development can be considered in the elastic design of the frame truss. The strength and stability design formulas suggested in this paper are reasonable and are verified using tests.
(2) For the plastic development of materials, the truss stiffness calculated by line element FEM should be reduced by a factor 0.68 , and the story drift angle calculated by line element FEM should be enlarged by a factor of 1.50 . The maximum ultimate story drift angle is better limited to $1 / 100$.

(3) Throughout the test process, the columns are working in the elastic state. When the horizontal load is large, the plastic strain is mainly distributed at the middle of the truss, and the ultimate failure position is at this location, which indicates that the frame obeyed the design principle of "strong column and weak beam."

(4) Because inclined braces change the load transmission path, the failure position occurs in the middle segment of the truss. The strains of beam-column joint are quite small, according to the test and finite element analysis, and the inclined braces play an important role in protecting joints, which shows that the frame obeys the design principle of "strong joint and weak member" [20].

(5) The frame failure mode is the flexural buckling of web members in the middle of the truss, which are the compression-bending members subjected to axial force and biaxial bending moments; good plasticity 
develops at the ends of web members before they lose stability, so this failure mode is reasonable.

\section{Notations}

\section{The following symbols are used in this paper:}

$$
N:
$$

Design values of max axial force of member-pressure takes negative values; tension takes positive values

$M_{x}$ : Design value of $\max$ bending moment around the $x$-axis of member

$M_{y}$ : Design value of max bending moment around the $y$-axis of member

$A_{n}:$

$W_{\text {inx }}$ :

$W_{\text {iny }}$ :

$\gamma_{1 x}=\gamma_{2 x}=\gamma_{3 x}=\gamma_{4 x}=1.05$

$\gamma_{1 y}=\gamma_{2 y}=1.05$ :

$\gamma_{3 y}=\gamma_{4 y}=1.2$ :

$\varphi_{x}:$

$\varphi_{y}:$

$W_{i x}:$

$W_{i y}:$

A:

$E:$

$\lambda_{x}:$

$\lambda_{y}:$

$\beta_{m x}$ :

$\beta_{m y}:$

$\beta_{t x}:$

$\beta_{t y}:$
Net sectional area of member

Net sectional modulus of points $i$ around $x$-axis Net sectional modulus of points $i$ around $y$-axis

Plastic development coefficients of points 1-4 around $x$-axis Plastic development coefficients of points 1-2 around $y$-axis Plastic development coefficients of points 3-4 around $y$-axis Stability coefficients of axial compression member around strong $x$-axis Stability coefficients of axial compression member around weak $y$-axis Cross-sectional modulus of points $i$ around $x$-axis Cross-sectional modulus of points $i$ around $y$-axis Cross-sectional area Elastic modulus Slenderness ratio around $x$-axis

Slenderness ratio around $y$-axis In-plane equivalent bending moment In-plane equivalent bending moment coefficients around $y$-axis Out-of-plane equivalent bending moment coefficients around $x$-axis Out-of-plane equivalent bending moment coefficients around $y$-axis. coefficients around $x$-axis

\section{Conflict of Interests}

The authors declare that there is no conflict of interests regarding the publication of this paper.

\section{Acknowledgment}

This work was supported by the National Natural Science Foundation of China (51278010).

\section{References}

[1] A. L. Zhang and X. C. Liu, "The new development of industrial assembly high-rise steel structure system in China," in Proceedings of the 10th Pacific Structural Steel Conference (PSSC '13), pp. 976-981, Singapore, October 2013.

[2] Y. Wen, Study on the System of Urban Residential Housing Which Meets Industrialized Construction, Xi'an University of Architecture and Technology, Xi'an, China, 2005.

[3] L. Jaillon and C. S. Poon, "The evolution of prefabricated residential building systems in Hong Kong: a review of the public and the private sector," Automation in Construction, vol. 18, no. 3, pp. 239-248, 2009.

[4] T. Dao and J. van de Lindt, "Seismic performance of an innovative light-frame cold-formed steel frame for midrise construction," Journal of Structural Engineering, vol. 139, no. 5, pp. 837848, 2013.

[5] W. Wang, Y. Y. Chen, Y. C. Yu et al., "Floor-by-floor assembled steel braced structures for prefabricated buildings," Building Structure, vol. 42, no. 10, pp. 48-52, 2012.

[6] L. H. Teh and B. P. Gilbert, "Net section tension capacity of coldreduced sheet steel channel braces bolted at the web," Journal of Structural Engineering, vol. 139, no. 5, pp. 740-747, 2013.

[7] X. X. Zha, L. L. Wang, and S. T. Zhong, “The method of constructing mutil-storied used shipping container buildings and the deduction of practical formula about structural security," Building Structure, vol. 40, no. 6, pp. 462-465, 2010.

[8] J. Zou, Suitability Analysis on Application of Steel Residential Building System in China, Tongji University, Shanghai, China, 2008.

[9] E. Hotała and K. Rykaluk, "Failure state of steel roof structure of the show-sports hall during assembly," Archives of Civil and Mechanical Engineering, vol. 12, no. 1, pp. 41-48, 2012.

[10] F. Case, A. Beinat, F. Crosilla, and I. M. Alba, "Virtual trial assembly of a complex steel structure by Generalized Procrustes Analysis techniques," Automation in Construction, vol. 37, pp. 155-165, 2014.

[11] H. Festjens, G. Chevallier, and J.-L. Dion, "A numerical tool for the design of assembled structures under dynamic loads," International Journal of Mechanical Sciences, vol. 75, pp. 170-177, 2013.

[12] M. Saranik, D. Lenoir, and L. J\&apos; ez\&apos; equel, "Shaking table test and numerical damage behaviour analysis of a steel portal frame with bolted connections," Computers and Structures, vol. 112-113, pp. 327-341, 2012.

[13] X. Y. Gong and H. Yan, "Discussion on application of prefabricated houses in foreign countries," Industrial Construction, no. 8, pp. 17-19, 2001.

[14] G. B. Li and Y. Z. Zhang, "On the developing process of constructional buildings in China," Journal of Chongqing Institute of Technology, no. 9, pp. 50-54, 2006. 
[15] Q. S. Yang, B. Li, and N. Yang, "Aseismic behaviors of steel moment resisting frames with opening in beam web," Journal of Constructional Steel Research, vol. 65, no. 6, pp. 1323-1336, 2009.

[16] Y. C. Lin, "Behavior of a steel coupled beam moment frame based on nonlinear analyses," Journal of Constructional Steel Research, vol. 99, pp. 10-17, 2014.

[17] D. Anderson, "Design of unbraced multi-storey steel frames," Journal of Constructional Steel Research, vol. 62, no. 11, pp. 11711177, 2006.

[18] GB/T 1591. High Strength Low Alloy Structural Steels, China Standards Press, 2009.

[19] GB50017, Code for Design of Steel Structures, China Building Industry Press, 2013.

[20] GB50011. Code for Seismic Design of Buildings, China Planning Press, 2010. 

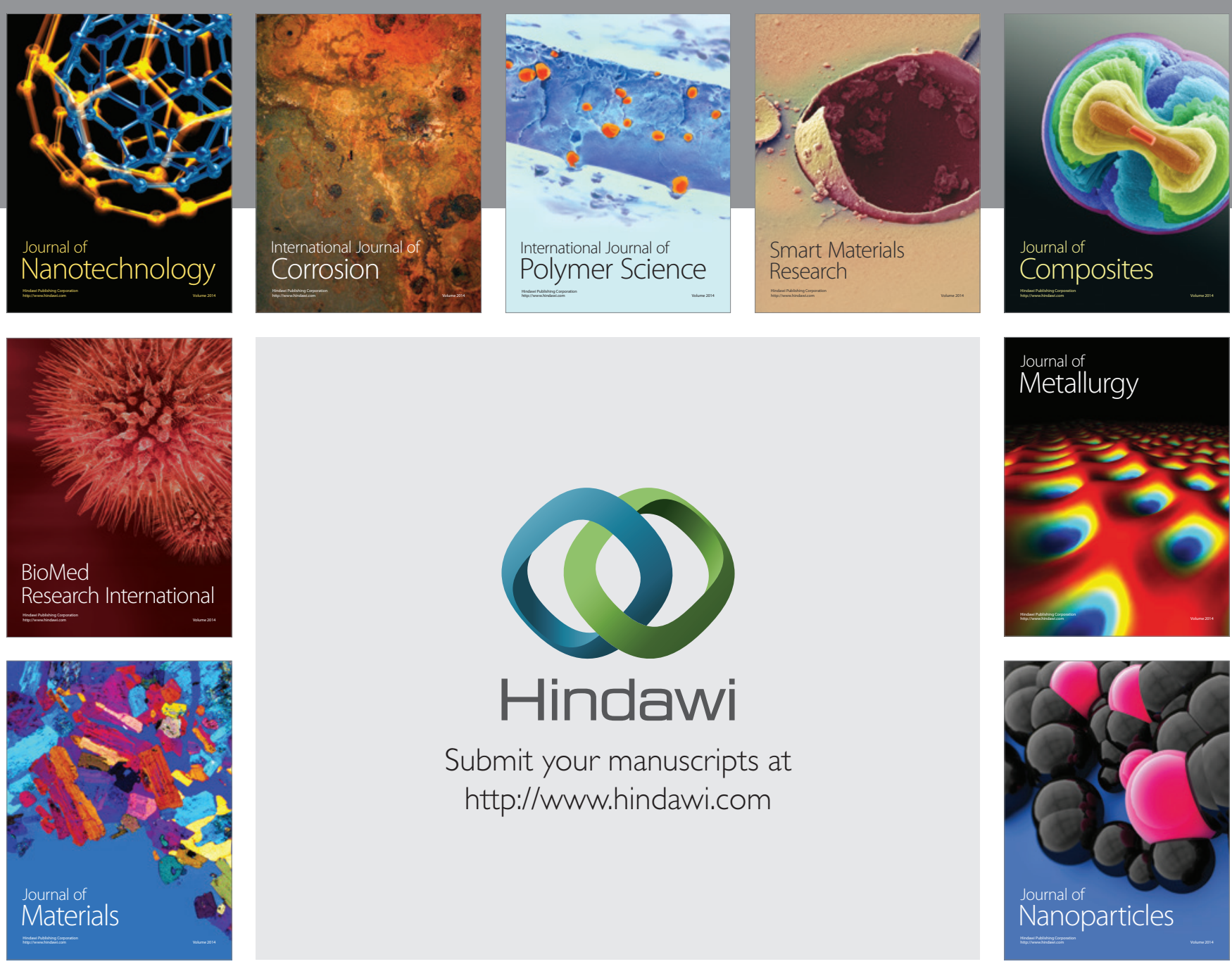

Submit your manuscripts at http://www.hindawi.com
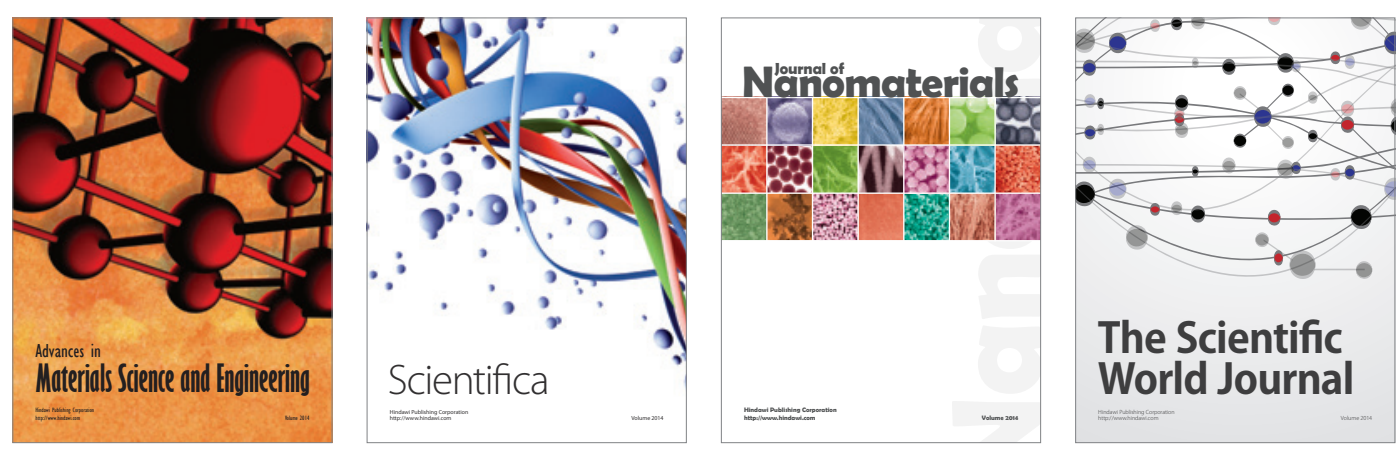

\section{The Scientific World Journal}
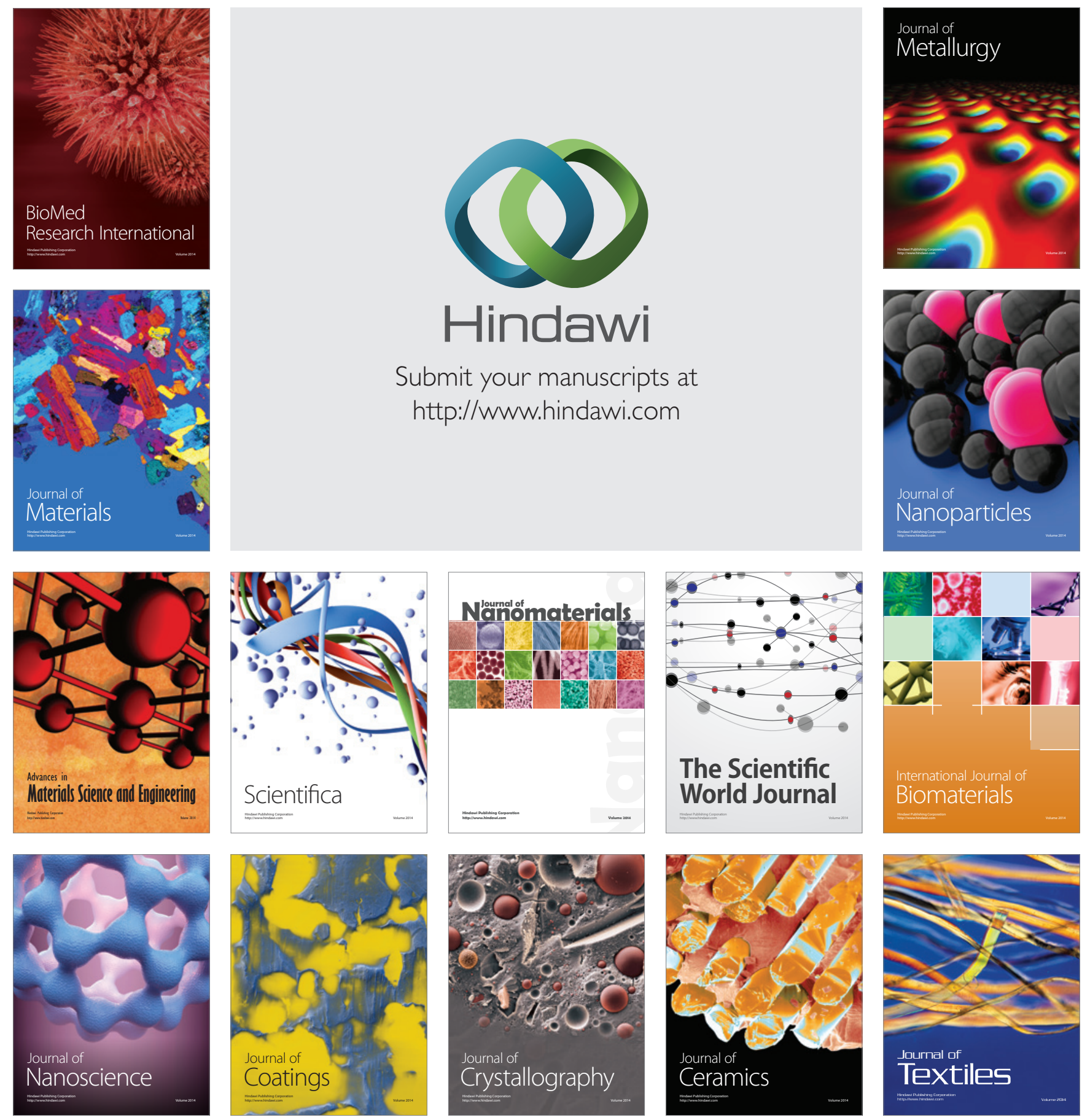